\title{
VICENTE GARCÍA DE LA HUERTA ANTE LA TRADUCCIÓN: LA «ADVERTENCIA»-PRÓLOGO DE XAYRA
}

\author{
Jesús Cañas Murillo \\ UNIVERSIDAD DE EXTREMADURA \\ jcanas@unex.es
}

\section{RESUMEN}

Estudio de las ideas sobre la forma de efectuar traducción de calidad, y sobre la labor del traductor, defendidas por Vicente García de la Huerta en la «Advertencia del traductor», que sitúa al frente de su tragedia Xayra o La fe triunfante del amor y cetro. La composición de este prólogo es situada en su contexto, y la polémica que se desencadenó a raíz de su publicación, es pormenorizadamente tratada en el artículo. Como complemento del trabajo, se reproduce, respectando grafía y puntuación originales, la propia «Advertencia del traductor» compuesta por el ilustrado español del siglo XVIII.

Palabras Clave: Historia literaria; Siglo XVII español; Ilustración; Erudición; Traducción; Vicente García de la Huerta.

\section{Abstract}

Study of the ideas on the way of effecting qualit translation, and on the translator's work, defended by Vicente Garcia de la Huerta in the «Advertencia del traductor», which it places at the head of his tragedy Xayra or The Triumphant Faith over the Love and Sceptre. The composition of this prologue is placed in his context, and the controversy that freed itself immediately after his publication, is treated in detail in the article. Complementing the work, is reproduced, respecting original spelling and punctuation, own «Advertencia del traductor», by the Spanish Illustrated of the 18th century. 
KEY WORDS: Literary History; Spanish 18th Century; Enlightenment; Erudition; Translation; Vicente García of the Garden.

\section{UNA «ADVERTENCIA» POLÉMICA}

Una de las múltiples polémicas en las que Vicente García de la Huerta, — «Entre los Fuertes de Roma, Antioro, entre los Arcades Alethophilo Deliade»'—, se vio envuelto a lo largo de su vida ${ }^{2}$, giró en torno a las ideas que defendía sobre el problema de cómo hacer una correcta traducción de obras extranjeras al castellano. La disputa tuvo lugar, en torno al año 1784, con motivo de la publicación de La Fe triunfante del Amor y Cetro. Tragedia en que se ofrece a los aficionados la justa idea de una traducción poética. Por Vicente García de la Huerta, libro impreso en Madrid, por Pantaleón Aznar, en 1784. En esta obra el extremeño reelabora una versión anterior de la tragedia Zaire de Voltaire, difundida como anónima en Barcelona, e impresa, en esa localidad, en dos ocasiones, la segunda en 1782. Esta versión fue, al parecer, debida a Pablo de Olavide, según había sugerido Cotarelo en su día ${ }^{3}$ y según recoge Juan Antonio Ríos, siguiendo a Francisco Lafarga ${ }^{4}$ :

La Fe triunfante... es una versión de la Zaire de Voltaire (Oeuvres completes, II, París, Societé Litteraire, 1784), basada en una traducción que de la misma hizo Pablo de Olavide, publicada con el título de La Zaida en Barcelona por Gubert y Tutó, s. a., reeditada en la misma ciudad y por el mismo editor en 1782 y en Salamanca, F. de Tóxar, s. a. Según Francisco Lafarga, la versión de Olavide fue escrita alrededor de 1765-1766 (Voltaire en España, 1734-1835, Barcelona, UB, 1982, p. 169).

En la publicación del texto de Don Vicente hecha por Pantaleón Aznar, se incluye un prólogo en la que el zafrense explica los objetivos perseguidos con su labor, que no eran otros sino ofrecer un modelo de cómo ha de realizar su tarea un traductor que desease ofrecer a sus receptores un producto digno, de calidad, y a la altura de su siglo. El extremeño, además, censuraba el trabajo que, en este campo, se había hecho en otras ocasiones en España.

${ }^{1}$ Como se informa en la portada de la primera impresión de su tragedia La Fe triunfante del Amor y Cetro. Tragedia en que se ofrece a los aficionados la justa idea de una traducción poética. Por Vicente García de la Huerta, Madrid, Pantaleón Aznar, 1784.

2 Cf. Jesús Cañas Murillo (2013), La disputa del Theatro Hespañol, de Vicente García de la Huerta: cronología de una controversia, Cáceres, Universidad de Extremadura (Trabajos del Departamento de Filología Hispánica, 28); y Jesús Cañas Murillo (2013), «Don Vicente y sus disputas», «El enfrentamiento por La Música», «La polémica por el Elogio del Excmo. Sr. D. Antonio Barceló», "Otras confrontaciones, otros combatientes, y, sobre todo, Forner», «La lucha por el Theatro Hespañol, o todos contra García de la Huerta», en «Introducción» a Vicente García de la Huerta, Theatro Hespañol. Prólogo del Colector, edición, introducción y notas de Jesús Cañas Murillo, Málaga, Universidad de Málaga (Número monográfico. Anejos de Analecta Malacitana, 87), pp. 71-136.

3 Cf. Emilio Cotarelo y Mori (1897), Iriarte y su época, Madrid, Establecimiento Tipográfico «Sucesores de Rivadeneyra», pp. 69-70, nota 4.

${ }_{4}$ Juan Antonio Ríos Carratalá (1987), Vicente García de la Huerta (1734-1787), Badajoz, Departamento de Publicaciones Diputación Provincial (Colección Rodríguez Moñino, 6), pp. 164-171. La cita está tomada de la segunda edición, incluida en la versión publicada, en 2009, en la Biblioteca Virtual Miguel de Cervantes, de la Universidad de Alicante, en la siguiente dirección de internet: http://bib.cervantesvirtual.com/FichaObra. html?Ref=32316. La versión está sin paginar, pero la cita se incluye en la nota 133 . 
Las afirmaciones incluidas por García de la Huerta en la «Advertencia del traductor», —el prólogo al que nos referimos-, inserta en la edición de su Xayra o La Fe triunfante del Amor y Cetro, no gustaron a algunos de sus lectores. Voces críticas empezaron a levantarse contra él, censurando las ideas expuestas por el zafrense. Entre esas voces se encontraban las de enemigos habituales de Don Vicente, como la de Tomás de Iriarte, la de Juan Pablo Forner, quizás las de Samaniego y Vargas Ponce 5 .

Los ataques de sus oponentes, como había sucedido en otras ocasiones, no acobardaron al escritor extremeño. El zafrense compuso, contra ellos, diversas obras por estos años. Tal vez estuviera pensando en sus detractores, - en general, pero, también, en particular, en los detractores del prólogo de la Xayra - , cuando redactó los versos pertenecientes a su texto, más o menos de 1785, titulado De un dístico burlesco de Lope de Vega ${ }^{6}$. También, quizá, los tendría, de algún modo, en mente cuando compuso su sátira El loco de Chinchilla. Fábula a la moda, esto es, insulsa y frívola ${ }^{7}$, de 1784, que, según algunos, como Cotarelo ${ }^{8}$, dirigió contra Juan Pablo Forner, - con motivo de la aparición de su obra El asno erudito - aunque, según otros, se trata del «romancillo contra Iriarte y Samaniego» al que se refiere Gaspar Melchor de Jovellanos en una carta, que escribe, en Madrid, en julio de 1784, a Cándido María Trigueros ${ }^{9}$ Y, contra todos ellos, fue compuesta la obra más contundente que les dedicó, un poema que se difundió en manuscrito en los círculos culturales del momento, y que fue conocido con el nombre de El pedo dispersador. Fábula medio verdad y medio mentira, también identificado, en algunas versiones, como el El pedo extreminador. Caga-Siete. Fábula medio verdad y medio mentira, y El pedo dispertador o Caga siete. En ella se refiere a sus contrarios maledicentes de la siguiente forma ${ }^{10}$ :

Del Traductor de la Xaira

féridos de la Advertencia, murmuraban en un corro siete sabios de la legua.

Cada qual se iba apropiando una de las indirectas, mui pagado de no estar comprehendido en todas ellas.

${ }_{5}$ Cf. Jesús Cañas Murillo (2013), La disputa del Theatro Hespañol, de Vicente García de la Huerta: cronología de una controversia; y los capítulos de la «Introducción» a Vicente García de la Huerta, Theatro Hespañol. Prólogo del Colector, edición, introducción y notas de Jesús Cañas Murillo, citados en nota anterior.

${ }_{6}$ Vicente García de la Huerta (1997), Poesías, edición, introducción y notas de Miguel Ángel Lama, Mérida, Editora Regional de Extremadura (Rescate, 14), pp. 501-502.

7 Vicente García de la Huerta (1997), Poesías, ed. Miguel Ángel Lama, citada, pp. 484-486.

${ }^{8}$ Emilio Cotarelo y Mori (1897), Iriarte y su época, citado, pp. 262 y 262-263, nota 3.

9 Ver, por ejemplo, Gaspar Melchor de Jovellanos (1984), Obras completas. Tomo I. Obras literarias, ed. José Miguel Caso González, Oviedo, Centro de Estudios del Siglo XVIII-Ilustre Ayuntamiento de Gijón (Colección de Autores Españoles del siglo XVIII, 22-1), p. 212.

${ }^{10}$ Utilizo la versión reproducida por René Andioc (1993) en su artículo «¿De estornudos, flatos, y otros modos de «dispersar». (Huerta y los fabulistas: un nuevo poema satírico)», Dieciocho, XVI, 1-2, pp. 25-48 reimpreso en René Andioc (2005), Del siglo XVIII al XIX. Estudios histórico-literarios, Zaragoza, Universidad de Zaragoza, pp. 347-373 - El texto, en pp. 26-27. También puede consultarse el texto completo en Vicente García de la Huerta (1997), Poesías, ed. Miguel Ángel Lama, citada, pp. 487-492; y varias versiones del mismo en Miguel Ángel Lama (1990), «Vicente García de la Huerta desde la librería de Copín. Dos versiones inéditas de una sátira tremenda», Anuario de Estudios Filológicos, XIII, pp. 151-159 (el texto, en pp. 155-159). 
Y en ella detalla el remedio que adoptó para acabar con tal grupo de, según él, ridículos murmuradores:

Descubre Huerta a este t[iem]po

la ridícula asamblea

y ocúrresele un arbitrio

de burlarse y disolverla.

Arrímase poco a poco, y quando ya estuvo cerca, el ruin concilio apestando, un tronante pedo suelta.

Aturdidos del estruendo, vuelven todos las cabezas, y al verle más aturdidos, se escabullen y dispersan.

Hácese público el caso, todo el mundo celebra del Pedo Dispersador, la ridícula historieta.

De suerte que aun los muchachos gritan quando a alguno encuentran:

Allá va uno de los siete

en que se ha cagado Huerta.

No obstante, aparte de esta contestación burlesca, a sus atacantes, por causa de la Xayra, la respuesta seria más fuerte que les dedica, se halla en la segunda edición del texto de la tragedia y de su «Advertencia del traductor», incluida en el volumen Obras poeticas de D. Vicente Garcia de la Huerta. Segunda edicion. Tomo I. Tragedias. Suplemento al Theatro Hespañol, publicado, «Con licencia», en Madrid, por Pantaleon Aznar, en 1786 [MDCCLXXXVI]. Se trata de una «Nota», ubicada entre la mencionada «Advertencia del traductor» y el texto de la tragedia. En ella se puede leer lo siguiente:

NOTA: En la primera edicion de esta Advertencia salieron contra ella y su Autor varias sátyras, a que se contexta ahora con la reimpresion literal de ella en prueba del desprecio, que entonces le merecieron ${ }^{11}$.

Don Vicente, en definitiva, se reafirma fuertemente en su postura, sin plantearse, siquiera como posiblilidad, ningún tipo de rectificaciones ni matizaciones.

${ }_{11}$ Obras poeticas de D. Vicente Garcia de la Huerta. Segunda edicion. Tomo I. Tragedias. Suplemento al Theatro Hespañol ha sido paginado de una manera peculiar. Cada tragedia tiene su propia paginación, independiente del resto. Los preliminares, entre los cuales se incluyen la «Advertencia del traductor», y la presente «Nota», carecen de algún tipo de numeración. La «Advertencia del traductor» ocupa las primeras quince páginas, sin numeración, del apartado del volumen dedicado a la Xayra, que se encabeza con una portadilla propia. La «Nota» se ubica en la página 16 sin numerar. 


\section{UNAS IDEAS SOBRE LA TRADUCCIÓN EN SU CONTEXTO}

La «Advertencia del traductor» de Vicente García de la Huerta se redacta a raíz de la composición de su tragedia La Fe triunfante del Amor y Cetro, también conocida como Xayra. La obra quiere ser una Tragedia en que se ofrece a los aficionados la justa idea de una traducción poética. Por Vicente García de la Huerta, como ya se indica en la portada de su primera edición, impresa en Madrid, por Pantaleón Aznar, en 1784, y como se reitera, igualmente, en la segunda edición de Madrid, Pantaleon Aznar, $1786^{12}$.

La aparición de esta tragedia coincidió con un momento de cierta remontada en la biografía de Don Vicente, tras su periodo de destierro y postración ${ }^{13}$. Son unos años en los que protagoniza ciertos acontecimientos positivos para él. Son instantes en los que, la Real Academia de Bellas Artes de San Fernando, en 1778, le va a encargar, para la «junta general que se celebró para la distribucion de premios, el dia XXV de julio de MDCCLXXVIII», unos Endecasylabos «que recitó» con motivo de esa reunión plenaria ${ }^{14}$. Es época en la que, el 14 de diciembre de 1778, puede ver representada públicamente, por primera vez en Madrid, en el teatro del Príncipe, su Raquel, que obtiene una notable aceptación por parte de sus espectadores. Y en la que, en 1778 y 1779, ve editados, en Madrid, en la Imprenta de Antonio de Sancha, los dos volúmenes de que constan sus Obras poéti$\operatorname{cas}^{15}$. También, por estos años, recibe encargos de censuras por parte del Consejo de Castilla; y la prestigiosa Real Sociedad Económica Vascongada de Amigos del País lo nombra socio honorífico. Mantiene buenas relaciones con parte de la nobleza, la cual solicitaba composiciones suyas para ser montadas en sus teatros y representaciones particulares ${ }^{16}$. En este ambiente, y, quizá, fruto de estas demandas, pudo efectuar la composición de otras dos de sus tragedias, Agamenón vengado, de $1778^{17}$, representada una vez en el domicilio particular de un noble, y La Fe triunfante del amor y cetro, de 1784.

La Fe triunfante del amor y cetro, o Xayra es, con frecuencia, simplemente mencionada por la crítica como traducción de la tragedia Zaire de Voltaire ${ }^{18}$. No obstante, García de la Huerta, —lo advierte en su «Advertencia del traductor»—, reelabora una

12 Obras poeticas de D. Vicente Garcia de la Huerta. Segunda edicion. Tomo I. Tragedias. Suplemento al Theatro Hespañol. Con licencia, en Madrid, por Pantaleon Aznar, MDCCLXXXVI [1786].

${ }_{13}$ Cf. Jesús Cañas Murillo (2013), «Etapas de su biografía», en «Introducción» a Vicente García de la Huerta, Theatro Hespañol. Prólogo del Colector, ya citada, pp. 15-23.

${ }_{14}$ Vicente García de la Huerta, Endecasylabos, que recitó en la Real Academia de S. Fernando en la junta general que se celebró para la distribucion de premios el dia XXV de julio de MDCCLXXVIII D. Vicente Garcia de la Huerta [...]. S. 1., s. i., s. a. [1778].

15 Vicente García de la Huerta (1778-1779), Obras poéticas. Madrid, Antonio de Sancha, 2 vols.

${ }^{16}$ Cf. Juan A. Ríos (1988), «Introducción» a su edición de Raquel de Vicente García de la Huerta, Madrid, Cátedra (Letras Hispánicas, 5), pp. 17-18.

${ }_{17}$ Agamenón vengado, al igual que el resto de las tragedias del extremeño, se publicó en el volumen Tragedias de D. Vicente Garcia de la Huerta. Suplemento al Theatro Hespañol, impreso en Madrid, por Pantaleón Aznar, en 1786.

18 Margarita Santos Zas (1999), «De Zaïre de Voltaire a Xayra de García de la Huerta», en VV. AA., Homenaxe ó profesor Camilo Flores, tomo I, Santiago de Compostela, Universidad de Santiago de Compostela, pp. 457-479. Sobre traducciones, y en especial de Voltaire, cf. VV. AA. El teatro europeo en la España del siglo XVIII, ed. Francisco Lafarga, Lérida, Universidad de Lérida, 1997; José Antonio Sabio Pinilla (ed.) (2009), La traducción en la época ilustrada (Panorámicas de la traducción en el Siglo XVIII), Granada, Editorial Comares (Interlingua); y de Francisco Lafarga (1977), «Traducciones españolas de Zaire de Voltaire en el siglo XVIII», Revue de Littérature comparée, LI, pp. 343-355, y Voltaire en España (1734-1835), Barcelona, Universidad de Barcelona, 1982 (ver, especialmente, pp. 171-174). 
traducción anterior, anónima, impresa en Barcelona, y allí reimpresa en 1782. Su objetivo, —antes lo destacábamos-, era servir de punto de referencia a los traductores españoles, mostrarles, con su ejemplo, cómo debían realizar correctamente su trabajo, juzgado deficiente por el extremeño. Ni el público ni la crítica parecieron dispensar una destacada atención a esta obra. No fue representada en vida del autor. Sólo en 1804 subió a las tablas del Teatro de los Caños del Peral, de Madrid, los días 22, 23, 24 y 29 de abril, el 20 de mayo, el 29 de julio, y el 5 de diciembre. Y desde este año no vuelve a ser montada hasta 1806, fecha en la que se escenifica, también en el Teatro de los Caños del Peral, el 1 de mayo, y, en el Teatro del Príncipe, también madrileño, los días 22, 23 y 24 de octubre ${ }^{19}$.

El hecho de que García de la Huerta quisiera dar lecciones sobre cómo hacer una buena traducción, a través de su propia obra, y que teorizase sobre el particular, por medio de un texto preliminar adjunto, no es extraño en el mundo cultural español de la Ilustración ${ }^{20}$. Otras propuestas similares existieron. Como la ofrecida por José Mor de Fuentes y Diego Clemencín en su Ensayo de traducciones que comprende la germanía, el agrícola y varios trozos de Tácito, con algunos de Salustio, un discurso preliminar, y una epístola á Tácito (Madrid, en la Oficina de D. Benito Cano, 1798), perfectamente estudiado por Joaquín Álvarez Barrientos ${ }^{21}$. Como la contenida en los trabajos realizados por Leandro Fernández de Moratín en este campo, y en los que ahora nos vamos a centrar.

Leandro Fernández de Moratín, Inarco Celenio, fue uno de los más insignes traductores de piezas dramáticas del periodo ${ }^{22}$. A él se deben tres importantes obras de esta clase, una versión de Hamlet, de William Shakespeare, y sendas versiones de La escuela de los maridos y El médico a palos, ambas de Molière ${ }^{23}$. Abarcó, también, otros géneros en el campo de la traducción. A él se debe una importante versión del Cándido de Voltaire ${ }^{24}$, titulada Cándido o el optimismo, publicada en Cádiz, en 1838, aunque acabada en $1814^{25}$.

${ }^{19}$ Cf. René Andioc y Mireille Coulon (2008), Cartelera teatral madrileña del siglo XVIII (1708-1808), Madrid, Fundación Universitaria Española, 2 vols., segunda edición corregida y aumentada; tomo I, pp. 514517, 531, y 533; y tomo II, p. 895.

${ }^{20}$ Cf. Francisco Lafarga (ed.), El teatro europeo en la España del siglo XVIII, citado; y José Antonio Sabio Pinilla (ed.), La traducción en la época ilustrada, citado.

21 Joaquín Álvarez Barrientos (2004), «Literatura y casticismo: Mor de Fuentes y su Ensayo de traducciones», en «Un hombre de bien». Saggi di lingue e letterature iberiche in onore di Rinaldo Froldi, I, a cura di Patrizia Garelli e Giovanni Marchetti, Bolonia, Edizioni dell»Orto, pp. 21-30.

22 Jesús Cañas Murillo (1999), «Leandro Fernández de Moratín, traductor y adaptador dramático», Anuario de Estudios Filológicos, XXII, pp. 73-98; y «Leandro Fernández de Moratín, traductor dramático», en $L a$ traducción en España (1750-1830). Lengua, literatura, cultura, ed. Francisco Lafarga, Lérida, Universidad de Lérida, 1999, pp. 463-475. Giuseppe Carlo Rossi (1974), «Moratín traductor», en su libro Leandro Fernández de Moratín. Introducción a su vida y obra, Madrid, Cátedra, pp. 117-122.

${ }^{23}$ René Andioc (1996), «Más sobre traducciones castellanas de Molière en el siglo XVIII», en Teatro español del siglo XVIII, ed. Josep Maria Sala Valldaura, Lérida, Universidad de Lérida, 2 vols., vol. I, pp. 4563; y «Moratín traducteur de Molière», en Hommage des Hispanistes Français a Nöel Salomon, Barcelona, Laia, 1979, pp. 49-72.

${ }^{24}$ Giuseppe Carlo Rossi (1974), «Moratín traductor», en Leandro Fernández de Moratín. Introducción a su vida y obra, Madrid, Cátedra, pp. 117-122. Sobre Cándido vid. p. 122.

${ }^{25}$ Cándido o el optimismo, de Voltaire. Traducido por Leandro Fernández de Moratín. Cádiz, Imp. de Santiponce, 1838. Esta versión ha sido reimpresa modernamente en varias ocasiones. Así, Madrid, Ciencia Nueva (Los Clásicos), 1967 (ed. de Jesús Munárriz Peralta); Barcelona, 1970 (en M. Palomo, Maestros franceses, II); Madrid, Libra (Colección Púrpura), 1972. 
Las traducciones realizadas por Leandro Fernández de Moratín en el campo de la dramática, han gozado históricamente de gran prestigio y aceptación ${ }^{26}$. Fueron reimpresas en repetidas ocasiones, incluso hasta nuestros días. De sus tres versiones, la primera en ser concluida fue Hamlet, al parecer hecha en 1794, aunque publicada, con introducción y notas, en $1798^{27}$. Tras ella fue terminada, en 1808, La escuela de los maridos ${ }^{28}$, 一representada en el teatro del Príncipe el 17 de marzo de 1812, e impresa en este mismo año ${ }^{29}$ - y El médico a palos, «representada en el teatro de Barcelona el dia 5 de diciembre de $1814 »^{30}$, y publicada en el mismo $1814^{31}$.

El trabajo realizado por Leandro Fernández de Moratín en el mundo de la traducción de obras dramáticas, tiene rasgos de peculiaridad. En sus escritos nos encontramos, a diferencia de lo que acontece en otros traductores del momento, con dos tendencias bien diferenciadas. Por un lado, identificamos al traductor de corte moderno, que intenta ser respetuoso, en términos generales, con el original que toma como base para su labor, y proporcionar, al lector interesado, una versión del mismo lo más ajustada posible a la que fue escrita por el autor que trata de poner en lengua castellana. Es la circunstancia en la que se halla su versión del Hamlet shakespeareano. Por otro lado, identificamos al adaptador que toma como base los escritos de un autor extranjero y los utiliza como material para ofrecer una versión, libre, de ellos que en muchos aspectos los separa, incluso de forma bastante sustancial, de su configuración primitiva. Es el caso en el que se encuentran sus propuestas sobre las comedias de Molière La escuela de los maridos y El médico a palos.

En todas sus versiones dramáticas, como sucede con la Xayra de García de la Huerta, se incluyen preámbulos en los que se proporcionan explicaciones sobre la labor realizada por Moratín, e, incluso, se teoriza sobre ella.

${ }^{26}$ Cf., de Jesús Cañas Murillo, «Leandro Fernández de Moratín, traductor y adaptador dramático», y «Leandro Fernández de Moratín, traductor dramático», citados.

27 [Leandro Fernández de Moratín], Hamlet. Tragedia de Guillermo Shakespeare, traducida e ilustrada con la vida del autor y notas críticas por Inarco Celenio. Madrid, Villalpando, 1798. Esta traducción y la adjunta biografía de Shakespeare han sido recogidas en Juan Carlos Rodríguez, Moratín o El arte nuevo de hacer teatro, Granada, Caja General de Ahorros, 1991. Sobre los datos externos de esta obra y las circunstancias de su composición, cf. Pilar Regalado Kerson, «Moratín y Shakespeare: un ilustrado español ante el dramaturgo inglés», en Actas de IX Congreso de la Asociación Internacional de Hispanistas, Frankfurt am Main, Vervuert Verlag, 1989, 2 tomos; tomo II, pp. 75-83. Los datos externos de la traducción se hallan en la p. 76. Ver, también, Pilar Regalado Kerson, «Leandro Fernández de Moratín: primer traductor de Shakespeare en castellano. Antecedentes y Preliminares a su versión de Hamlet», Dieciocho, 12, 1, 1989, pp. 45-65; y Philip Deacon, «La traducción de Hamlet de Leandro Fernández de Moratín», en Teatro clásico en traducción: texto, representación, recepción. Actas del Congreso Internacional. Murcia, 9-11 noviembre 1995, edición de Ángel-Luis Pujante y Keith Gregor, Murcia, Universidad de Murcia, 1996, pp. 299-308.

${ }_{28}$ [Leandro Fernández de Moratín] (1812), La escuela de los maridos. Comedia escrita en francés por Juan Bautista Molière, y traducida a nuestra lengua por Inarco Celenio. Madrid, Villalpando.

${ }^{29}$ Cf. «Advertencia», en Obras de Don Nicolás y de Don Leandro Fernández de Moratín, ed. Buenaventura Carlos Aribau, Madrid, Rivadeneyra (BAE, 2), 1846, p. 443.

30 «Advertencia», en Obras de Don Nicolás y de Don Leandro Fernández de Moratín, ed. Buenaventura Carlos Aribau, Madrid, Rivadeneyra (BAE, 2), 1846, p. 460.

${ }^{31}$ [Leandro Fernández de Moratín] (1814), El médico a palos. Comedia imitada por Inarco Celenio de la que escribió en francés J. B. Molière, con el título de El médico por fuerza. Madrid, I. Collado. Sobre los datos externos de estas dos últimas obras y las circunstancias de su composición, véase René Andioc (1979), «Moratín traducteur de Molière», en Hommage des Hispanistes Français a Nöel Salomon, Barcelona, Laia, pp. 49-72. 
Así, en la «Advertencia» situada al frente de la versión de Hamlet $^{32}$, el autor se encarga de explicar el verdadero sentido de su trabajo. Declara que «ha formado su traduccion sobre el original mismo» ${ }^{33}$. Expone cuál es su intencionalidad al realizar su tarea:

Si el traductor ha sabido desempeñar la obligación que se impuso de presentarle [Hamlet] como es en sí, no añadiéndole defectos, ni disimulando los que halló en su obra, los inteligentes deberán juzgarlo ${ }^{34}$.

Según él, el traductor debe respetar el espíritu del original, pero también «hacer hablar en castizo español á un estranjero» ${ }^{35}$. Esos son sus objetivos primordiales.

En la «Advertencia» que precede, en la edición de la Biblioteca de Autores Españoles ${ }^{36}$, al texto de La escuela de los maridos, versión de L'école des maris de Molière, quedan destacados algunos de los cambios que esta comedia contiene con respecto al original francés. En La escuela de los maridos las modificaciones de Moratín con relación al texto francés que le sirve de base, son mucho más abundantes que las que hallábamos en su versión del Hamlet shakespeareano, de manera que, en este caso, su trabajo, más que como traducción, habría que catalogarlo como adaptación ${ }^{37}$. En su «Advertencia» preliminar se justifica la realización de la adaptación, dado que el texto de Molière no es juzgado válido, en su versión primigenia, para ser presentado a la sociedad española del momento. Se explica que es necesario adecuarlo a las circunstancias del país, cambiar las costumbres, la ambientación, eliminar las digresiones sobre la moda, sobre los trajes, que se llevaba en Francia en el año 1661, hacer mención solamente de usos nacionales... Que es preciso motivar más «las salidas y entradas de los interlocutores ${ }^{38}$, añadir

á las ficciones de la astuta Isabel (llamada en la traduccion doña Rosa) todo el cúmulo de circunstancias indispensables para hacer el engaño verisímil, y de consiguiente disminuyó [...] la estupida credulidad de Sganarelle (don Gregorio) ${ }^{39}$.

Se especifica que el adaptador

Omitió en el diálogo muchas espresiones, que si fueron aplaudidas cuando se escribieron, ya no las sufre la decencia del teatro.

Hizo desaparecer en el caracter de Isabel la indecorosa desenvoltura con que abandonando

${ }^{32}$ Cf. Leandro Fernández de Moratín (1846), Hamlet, en Obras de Don Nicolás y de Don Leandro Fernández de Moratín, ed. Buenaventura Carlos Aribau, Madrid, Rivadeneyra (BAE, 2), pp. 473-560. La «Advertencia», en pp. 473-475.

33 Ibidem, p. 475.

34 Ibidem, pp. 473-474.

35 Ibidem, p. 474.

${ }^{36}$ Leandro Fernández de Moratín (1846), La escuela de los maridos. Comedia en tres actos en prosa, en Obras de Don Nicolás y de Don Leandro Fernández de Moratín, ed. Buenaventura Carlos Aribau, Madrid, Rivadeneyra (BAE, 2), pp. 442-459. La «Advertencia», en pp. 442-443.

37 Ya René Andioc (1979) señaló algunos cambios introducidos por don Leandro en su versión, en su memorable trabajo «Moratín traducteur de Molière», en Hommage des Hispanistes Français a Nöel Salomon, Barcelona, Laia, pp. 49-72. Ver, especialmente, pp. 62-67. Andioc (1982) completa este trabajo en sus estudios «Sobre Goya y Moratín hijo», Hispanic Review, 50, 2, spring 1982, pp. 119-132 (vid. especialmente p. 124 y nota 17); y «Más sobre traducciones castellanas de Molière en el siglo XVIII», en Teatro español del siglo XVIII, ed. Josep Maria Sala Valldaura, Lérida, Universidad de Lérida, 1996, 2 vols., vol. I, pp. 45-63.

${ }_{38}$ Leandro Fernández de Moratín, La escuela de los maridos, citado, p. 442.

39 Ibidem, p. 442. 
su casa, va derecha á la de su amante (á quien no conoce sino de vista) para entregarse en sus manos, y autorizarle á que disponga de ella á su voluntad ${ }^{40}$.

y que, en su escrito,

Nada hay $[\ldots .$.$] de los incidentes violentos que preparan el desenlace, cuando escondida la$ pupila [...], el galán desde la ventana, los dos hermanos, el comisario y el escribano desde la calle ajustan el casamiento, sin que se averigüe primero quién es la que se casa, y á la luz de un farol atropellan y firman un contrato de tal entidad [...]. El traductor desechó todo esto, y simplificando el desenredo, conservó la sorpresa, sin perjuicio de la verisimilitud: y en él, como en toda la comedia, añadió nuevos donaires cómicos, y nuevos rasgos característicos, para suplir con ellos lo que podia perderse en los pasajes que le fue necesario variar ó suprimir ${ }^{41}$.

El propio Moratín se encarga, —en el prólogo que situó al frente de su comedia, y que es, en parte, recogido en la «Advertencia» que encabeza el texto de la Biblioteca de Autores Españoles, y a la que antes nos hemos referido-, de explicar cuáles han sido las directrices y objetivos de su tarea:

Ha traducido á Moliere [...] con la libertad que ha creido conveniente para traducirle en efecto, y no estropearle; y de antemano se complace al considerar la sorpresa que debe causar [...] la poca exactitud con que ha puesto en castellano las espresiones del original, cuando hallen páginas enteras en que apenas hay una palabra que pueda llamarse rigurosamente traducida. ¿Quién le perdonará la osadía de omitir en su versión pasajes enteros, abreviarlos ó dilatarlos, alterar algunas escenas, conservar en otras el resultado, prescindir del diálogo en que las puso el autor, y sustituir en su lugar otro diferente? ${ }^{42}$

En su versión de Le médecin malgré lui de Molière, Don Leandro se sitúa en la misma línea de La escuela de los maridos. No se plantea, tampoco en esta ocasión, ofrecer una traducción literal de la pieza francesa. Proyecta una adaptación. En la «Advertencia» que encabeza el texto, inserta en el tomo segundo de la Biblioteca de Autores Españo$\operatorname{les}^{43}$, quedan recogidas las líneas generales del trabajo hecho por el autor. Se indica que

Simplificó la acción, despojándola de cuanto le pareció inútil en ella. Suprimió tres personajes, MM. Robert, Thibaut y Perrin, y por consiguiente dejó perder la graciosa escena segunda del primer acto, y la segunda del tercero, para no interrumpir la fábula con distracciones meramente episódicas, sujetándola á la estrecha economía que pide el arte ${ }^{44}$.

Se destaca la supresión de incidentes que aparecían en el argumento de la obra francesa:

Redujo á tres las cinco palizas que halló en la pieza original. Pasó en silencio la existencia inútil de un amante que no aparece en la escena, y esta omisión le facilitó el medio de dar á la resistencia obstinada de don Jerónimo un motivo mas cómico, y mas naturalidad al desenlace ${ }^{45}$.

40 Ibidem, p. 442.

41 Ibidem, p. 442.

42 Ibidem, p. 442.

${ }^{43}$ Leandro Fernández de Moratín (1846), El médico a palos. Comedia en tres actos en prosa, en Obras de Don Nicolás y de Don Leandro Fernández de Moratín, ed. Buenaventura Carlos Aribau, Madrid, Rivadeneyra (BAE, 2), pp. 460-472. La «Advertencia», en p. 460.

44 Ibidem, p. 460.

45 Ibidem, p. 460. 
Y los cambios introducidos en el lenguaje de los personajes:

Omitió igualmente las lozanías y espresiones demasiado alegres del supuesto médico, que no se hubieran tolerado en ningún teatro de España, y se hallan en la escena primera del primer acto, en las cuarta, quinta y sétima del segundo, y en la tercera del tercero de la obra francesa; y persuadido de que las imágenes asquerosas ni son donaires cómicos, ni deben presentarse jamás á un auditorio decente, omitió lo que hay de este género en la escena sesta, acto segundo, y en la quinta, acto tercero, del original ${ }^{46}$.

Se especifica que el texto, como el original, no va ser muy respetuoso con la norma de las unidades ( Esta obra no admite unidad de lugar ${ }^{47}$ ). Y se insiste en la idea de que la versión de la obra se hace con las vistas puestas en el público español que había de recibirla:

Moratín supo darla [a la traducción] todo el aire de originalidad que necesitaba para hacerla mas agradable al público español que habia de oirla ${ }^{48}$.

La labor desarrollada por Vicente García de la Huerta en su trabajo sobre el Zaire de Voltaire $^{49}$, se ubica en la misma línea en la que se hallan los trabajos de Leandro Fernández de Moratín sobre Molière. Él hace una adaptación de la obra original, para adecuarla a los gustos del público español que la iba a recibir. Y lo hace porque esa tarea queda adecuada al pensamiento sobre la labor propia del traductor, defendido por el zafrense, y expresado, y explicado, en la «Advertencia del traductor» que encabeza el texto de su Xayra. En ella, el extremeño, además de censurar el trabajo que, en este campo, se había hecho en otras ocasiones en España ${ }^{50}$ :

No han sido de [...] mérito [...] muchas [traducciones que aparecieron en España], que han ido saliendo [...], en que se vé infelizmente desfigurado el original, sin haber adquirido gracia alguna por esta libre maniobra.

El defecto mas freqüente en las traducciones de piezas Poéticas consiste, en querer aquellos que las hacen, conservar con una religiosidad pueril e impertinente la letra del original, con cuyo trabajo, por mas ímprobo que sea, no se logrará de ordinario otra cosa, que enervar la fuerza del Autor, a causa de la notable diferencia, que tienen entre sí las lenguas, no solo en quanto a su índole y frases, sino también en quanto a las ideas, conceptos y expresiones que les son peculiares.

incluye disquisiciones sobre las características que habrían de tener las traducciones aceptables $^{51}$ :

$\mathrm{Ni}$ es menor la diversidad que se observa en quanto a la misma Poesía con respecto a las varias naciones que la cultivan. Cada una tiene sus propriedades privativas, y su particular

\footnotetext{
46 Ibidem, p. 460.

47 Ibidem, p. 460.

${ }^{48}$ Ibidem, p. 460.

${ }^{49}$ Cf. Francisco Lafarga (1977), «Traducciones españolas de Zaire de Voltaire en el siglo XVIII», Revue de Littérature comparée, LI, pp. 343-355; y Ch. B. Qualia (1939), «Voltaire»s Tragic Art in Spain in the XVIIIth. Century», Hispania, XXII, pp. 273-284.

${ }_{50}$ Vicente García de la Huerta (1784), «Advertencia del traductor», en La Fe triunfante del Amor y Cetro. Tragedia en que se ofrece a los aficionados la justa idea de una traducción poética. Por Vicente García de la Huerta, Madrid, Pantaleón Aznar, pp. 3 y 4.

51 Vicente García de la Huerta, «Advertencia del traductor», citada, pp. 4-5, y 6.
} 
carácter, que quasi siempre es análogo al de los Naturales. A un Español, a un Oriental, a quienes la sublimidad y pompa de sus Poesías encanta justamente, sería insoportable una Poesía Francesa, si se la diesen traducida con su frigidez natural y characterística; del mismo modo que desagradaría á un Francés un pensamiento, una metháphora, y una comparación modelada a la Oriental, si se la presentasen con el fausto que tanto ofende a cierta nueva secta de Ami-Epigrammatistas, que de Francia ha pasado a Italia, y de rechazo ha contagiado a no pocos frívolos Españoles, que ya hallan atrevido, hinchado y monstruoso todo aquello que ni saben, ni pueden ellos hacer, y quanto no está a tiro de las debiles fuerzas de sus ingenios.

El Traductor debe tratar el Original cuya traducción emprende con toda la cortesanía que está obligado a observar aquel que lleva voluntariamente un huesped a su casa. Sería una enorme villanía en lugar de regalarle, según exige la urbanidad, el despojarle de sus vestidos proprios. Esto es puntualmente lo que hacen los malos y literales Traductores de Obras Poéticas; y asi como al que hospeda en su casa a otro, es indispensable el obsequio y regalo de su huesped, por la misma razón nunca se debe tener a mal que el Traductor realce los pensamientos del original; en lo que no hace otra cosa, que lo que inspiran la buena crianza y la razon.

Son ideas que, si no son iguales, guardan una evidente relación con las expuestas en los prólogos a las obras dramáticas, traducidas, y, especialmente, adaptadas, de Leandro Fernández de Moratín, de los que antes nos hemos ocupado. Lo mismo sucede con los usos que ambos exhiben en sus respectivas tareas como traductores.

\section{El pensamiento del autor en el prólogo de la Xayra}

Aun existiendo una identidad, en lo esencial, en el pensamiento y en las prácticas adoptadas, en el campo de la traducción, entre la obra de Vicente García de la Huerta, y la de otros autores de su época que abordan similares tareas, la labor del extremeño fue objeto de burlas, ataques y vituperios. La causa fundamental fue la tremenda antipatía que despertaba su figura, y, por ende, sus escritos, en muchos de sus contemporáneos, que se manifestaron como sus declarados enemigos, que no sólo adversarios. Sus detractores no se molestaban en tomar en verdadera consideración las razones que Don Vicente exponía en sus creaciones. Lo atacaban incluyera lo que incluyera en sus textos. Sólo porque la defensa de una determinada postura era realizada por él. De ahí que, hoy, intentando observar la realidad incluida en los textos de unos y otros con cierta imparcialidad y objetividad, nos puedan resultar, cuanto menos, chocantes ciertas polémicas entre autores del momento, cuando, leídos sus escritos por separado, pueden observarse sorprendentes concomitancias entre ambos. Es lo que sucede, en parte, entre propuestas defendidas por el zafrense y propuestas defendidas por el emeritense Juan Pablo Forner, uno de sus mayores oponentes y enemigos. O es lo que sucede en las ideas sobre la traducción expuestas y practicadas por Don Vicente, y en las ideas sobre la traducción expuestas y practicadas por Don Leandro Fernández de Moratín, también oponente del extremeño, con quien en repetidas veces polemizó ${ }^{52}$.

${ }^{52}$ Cf. Jesús Cañas Murillo (2013), La disputa del Theatro Hespañol, de Vicente García de la Huerta: cronología de una controversia; e «Introducción» a Vicente García de la Huerta, Theatro Hespañol. Prólogo del Colector, edición, introducción y notas de Jesús Cañas Murillo, ambos citados antes. 
Debido a estas circunstancias, y debido a las deturpaciones, y tergiversaciones, que el pensamiento de Vicente García de la Huerta ha tenido que padecer en boca de sus detractores, sobre los más diversos temas, y también sobre la traducción, lo más adecuado es conocer directamente su postura, sobre este último particular, acudiendo directamente a la fuente que la transmite. Por ello hemos decidido editar, a continuación, la «Advertencia del traductor» que abre las dos impresiones de la Xayra realizadas en vida de su autor, la impresa en Madrid, por Pantaleón Aznar, en 1784, y la impresa en Madrid, por Pantaleón Aznar, en 1786, a las que anteriormente hicimos referencia.

Reproducimos, corrigiendo las, escasísimas, erratas evidentes, -aunque señalándolas en la correspondiente nota a pie de página-, la versión de $1786^{53}$. Es la última que preparó Don Vicente antes de morir. En ella introduce modificaciones de grafías, con respecto a la versión de 1784, que responden a su último pensamiento sobre el particular, y a sus últimos usos, en correspondencia con la situación que encontramos en su Theatro $H_{e s p a n ̃ o l}{ }^{54}$. De ella respetamos grafía, —especialmente importante en este caso-, y, en lo posible, puntuación, con el fin de facilitar el conocimiento de los usos, en este campo, de la época, y de la archirrepetida «extraña ortografía» del zafrense, pero, en realidad, no tan «extraña», ni tan caprichosa e injustificada, ni tan extendida en toda su producción. Pero eso es otra historia, para otro momento, para otro lugar.

\author{
LA FE TRIUNFANTE \\ DEL AMOR Y CETRO, \\ $\mathrm{O}$ \\ XAYRA. \\ TRAGEDIA FRANCESA.
}

Pues ley, que al mundo todo une y concilia

en recíproco amor, solo es dictada

de eterna y celestial sabiduría. Act. I.

\title{
ADVERTENCIA \\ DEL TRADUCTOR
}

La aceptacion que logró esta Tragedia en sus primeras representaciones en el Theatro de París, el aplauso que la ha seguido desde entonces en todos los demás, y el merito que pueda tener, la han hecho mirar como una obra perfecta en su especie por los apasionados de la Dramática Francesa.

Esta idea ha movido a muchos, a traducirla a sus idiomas; pero dudo, que en ninguno haya tantas traducciones de ella como en el Castellano. Algunos traductores han desempeñado su empresa con aplauso; pero ninguno con tanta felicidad, a mi parecer,

\footnotetext{
${ }^{53}$ Incluida en Obras poeticas de D. Vicente Garcia de la Huerta. Segunda edicion. Tomo I. Tragedias. Suplemento al Theatro Hespañol. Con licencia, en Madrid, por Pantaleón Aznar, MDCCLXXXVI.

${ }^{54}$ Cf. Vicente García de la Huerta (2013), Theatro Hespañol. Prólogo del Colector, edición, introducción y notas de Jesús Cañas Murillo, citado.
} 
como una Dama de muy singulares talentos, que hizo una de las primeras traducciones que aparecieron en Hespaña. No han sido de igual merito otras muchas, que han ido saliendo posteriormente, en que se vé infelizmente desfigurado el original, sin haber adquirido gracia alguna por esta libre maniobra.

Otros por el contrario, ciñendose al texto baja y siervamente, no solo le han degradado de su dignidad, como debe suceder en toda traduccion literal; sino que, despojándole del auxilio de la Rima, mas necesaria a la Poesía Francesa, que a otra alguna, para disimular su frialdad Celtica, han agregado a sus traducciones la insipidéz del verso suelto, de que solo pueden gustar, los que no saben hacer otros, o los que se deleytan con Dramas en prosa.

El defecto mas freqüente en las traducciones de piezas Poéticas consiste, en querer aquellos que las hacen, conservar con una religiosidad pueril e impertinente la letra del original, con cuyo trabajo, por mas ímprobo que sea, no se logrará de ordinario otra cosa, que enervar la fuerza del Autor, a causa de la notable diferencia, que tienen entre sí las lenguas, no solo en quanto a su índole y frases, sino tambien en quanto a las ideas, conceptos y expresiones que les son peculiares.

$\mathrm{Ni}$ es menor la diversidad, que se observa en quanto a la misma Poesía con respecto a las varias naciones que la cultivan. Cada una tiene sus propiedades privativas, y su particular carácter, que quasi siempre es análogo al de los Naturales. A un Hespañol, a un Oriental, a quienes la sublimidad y pompa de sus Poesías encanta justamente, sería insoportable una Poesía Francesa, si se la diesen traducida con su frigidez natural y characterística; del mismo modo que desagradaria a un Francés un pensamiento, una metháphora y una comparacion modelada a la Oriental, si se la presentasen con el fausto que tanto ofende a cierta nueva secta de Anti-Epigrammatista, que de Francia ha pasado a Italia, y de rechazo ha contaminado a no pocos frívolos Hespañoles, que ya hallan atrevido, hinchado y monstruoso todo aquello que ni saben, ni pueden ellos hacer, y quanto no está a tiro de las debiles fuerzas de sus ingenios.

El vicio de estos serviles traductores es, el que reprende Cervantes en boca del Cura en el Escrutinio de los libros de Don Quixote con alusion a la traduccion del Orlando del insigne Poeta Ludovico Ariosto, hecha por el Capitan Don Gerónimo Ximenez de Urrea, Aragonés, de quien dice, que le quitó mucho de su natural valor; y lo mismo harán todos aquellos, que los libros de versos quisieron verter en otra lengua: que, por mucho cuidado que pongan y habilidad que muestren, jamás llegarán al punto que ellos tienen en su primer nacimiento.

El traductor debe tratar el Original, cuya traduccion emprende, con toda la cortesanía, que está obligado a observar aquel, que lleva voluntariamente un huesped a su casa. Sería una enorme villanía, en lugar de regalarle, segun exîge la urbanidad, el despojarle de sus vestidos proprios. Esto es puntualmente, lo que hacen los malos y literales traductores de Obras Poéticas; y así como al que hospeda en su casa a otro, es indispensable el obsequio y regalo de su huesped: por la misma razon nunca se debe tener a mal, que el traductor realce los pensamientos del original; en lo que no hace otra cosa, que lo que inspiran la buena crianza y la razon. De la observancia de este canon resulta, a mi parecer, el mayor merito de la traduccion del Amyntas de Torquato Taso, hecha por Don Juan de Jauregui, que se califica por la mejor que tenemos en nuestro idioma. 
No se adquirirá ciertamente esta alabanza Mr. Linguet, aquel Linguet por otra parte tan ingenuo, despreocupado y sabio. En el año de 1770. imprimió en París, con el titulo de Theatro Hespañol, una coleccion de comedias nuestras, traducidas en prosa Francesa, que dedicó a la Académia Hespañola en señal de su amor a la nacion y a su Dramática. No hablaré de la mala eleccion de las Piezas que contiene, ni del errado e inexâcto juicio que hace de ellas; reservando para el Theatro Cómico Hespañol, que tengo pronto para la prensa, tratar esta materia ${ }^{55}$; solo diré, que por falta de inteligencia de nuestra lengua, o por otra razon menos inocente, parece, que en aquellas traducciones no tubo otro fin, que el presentar a nuestros émulos nuevos motivos de alucinacion, para continuar en sus preocupaciones contra nuestro Theatro.

La primera comedia de esta coleccion es La Esclava de su Galan, una de las muchas incorrectas y defectuosas, con que inundó los Theatros el fecundísimo ingenio de Lope de Vega. Por estas razones es una tambien de las que apenas se representan, ni ahun por las Compañias que llaman de la Legua. En la misma version del titulo empieza el error del traductor, y la desfiguracion del original; pues la intitula La Constance a l' epreuve: esto es, La Constancia a prueba; o La mayor Constancia, o La prueba de la Constancia, sostituyendo una idea y expresion incircunscripta, vaga y comun a la precisa, determinada y privativa, que enuncia la constancia de una mujer, calificada, con la circunstancia de hacerse esclava de su Amante, para recobrar su afecto.

La primera Escena de esta comedia comienza, despidiendóse Elena de la amistad y trato de su Amante Don Juan con este verso:

Esto se acabó, Don Juan.

cuya expresion, sobre ser muy enérgica y graciosa en Castellano, envuelve cierto émphasis decoroso muy oportuno en la ocasion, en que se dice. Pero el Colector la traduce de este modo:

$$
\text { C' en est assez, Dom Jean. }
$$

esto es: Basta ya, Don Juan. Qualquiera, que sepa las dos lenguas, y ahun sin saberlas, conocerá la falta de exâctitud y puntualidad de esta traduccion, en la qual se comete además un triste despojo de la gracia que tiene la expresion y frase original. A este modo está vertida toda la comedia.

La segunda de la coleccion es el Domine Lucas; pero no aquel Domine Lucas de Cañizares, tan justamente aplaudido en nuestro Theatro, y que al de qualquier nacion de las mas preciadas de cultas, bastaria a dar honor por la gracia e ingenio, que recomiendan su composicion; sino otro Domine Lucas de Lope de Vega, que nada tiene comun con el de Cañizares mas que el titulo. Mr. Linguet oyó sin duda celebrar o vió representar (parece estubo algun tiempo en Hespaña) la célebre comedia de Cañizares, y al hacer su Theatro Hespañol, acordandose que habia una con este titulo muy aplaudida, creyendo, ser de Lope, encontraría en el tomo 17 de sus comedias, mas faciles de hallarse en Francia, que la Comedia suelta, de Cañizares, una con igual título, y sin

55 Cf. Vicente García de La Huerta (2013), Theatro Hespañol. Prólogo del Colector, edición, introducción y notas de Jesús Cañas Murillo, citado. Ver pp. 47, 50, 68, 136, y, sobre todo, 270-286, y sus notas correspondientes. 
mas exâmen, la incluyó en su coleccion, formando la traduccion de ella, no obstante ser una de las mas disparatadas de aquel ingenio, y como tal desconocida e ignorada de quasi todos los Hespañoles, y ahun de los mismos Cómicos, entre quienes no he hallado la menor noticia de ella.

La accion de esta Comedia pasa en la célebre Villa de Alba de Tormes; cuya circunstancia expone Lope para informar al Auditorio, segun reglas de buena Dramática, en el Prologo secreto, que se contiene en la primera escena, cuyos quatro primeros versos son los siguientes:

\section{FABRICIO.}

¿Qué os parece de este dia, Señor Fulgencio?

\section{FULGENCIO.}

Alba diferente ya,

Que está

de lo que en mi edad solia.

Mr. Linguet, o por ignorancia o por otra razon que no alcanzo, no solo no nombra la Villa de Alba aqui, ni en el resto de la traduccion, sin embargo de repetirse su nombre muchas veces en el original; pero ni ahun sostituye qualquiera otro pueblo en que se suponga la fábula; cuya falta, con otras muchas que tiene la traducción, agregada a las no pocas de que abunda la misma comedia, forman uno de los documentos con que Mr. Linguet quiere demostrar a los estrangeros el merito de nuestro Theatro: así es de acertado su juicio, quando hacen su censura. Bastan por ahora estas apuntaciones sobre el acierto de la coleccion y traducciones de este Sabio.

Entre las muchas que se han hecho de esta Tragedia, dos solamente se han dado a la estampa. Don Juan Francisco del Postigo, vecino de Cadiz, publicó la primera, impresa en aquella Ciudad en casa de Don Manuel Espinosa de los Monteros en el año de 1765. Está en versos pareados, cuya dura ley hace muchas veces decir a los no muy diestros, lo que no quieren, y esto sucede no pocas a este traductor. La segunda, que, segun pienso, es la que representaba la Compañia que seguia los Sitios, se imprimió en Barcelona, sin expresar el nombre del traductor, no hace muchos años, y se reimprimió en la misma Ciudad en el de 1782 por Carlos Gibert y Tutó. Esta es la que me ha servido de original; pues por su puntualidad demasiada puede reputarse por equivalente. He conservado en mi Paráphrasis algunos versos de ella, por no ser mi intento, ridiculizar estas obras, sino dar una idea justa del modo con que las deben emprender los aficionados a la traduccion $^{56}$ de piezas Poéticas.

Pienso, será muy oportuno, copiar aqui el primer discurso de Fátima, de una y otra traduccion, que es el principio de la Tragedia; para que, parangonados entre sí, puedan los que quisiesen, pasar a hacer el cotejo con el de mi Paráphrasis. En la traduccion de Postigo es como se sigue:

${ }^{56}$ En la versión de Obras poeticas de D. Vicente Garcia de la Huerta. Segunda edicion. Tomo I. Tragedias. Suplemento al Theatro Hespañol, que utilizamos como base, truducción, por errata. 


\section{FATIMA.}

¿Quién habia de pensar, o Zayda bella, que este sitio fatal y dura estrella nuevas te suscitase inclinaciones? ¿Qué esperanza, destino, o qué blasones tan lastimosos y funestos dias han ya mudado en tantas alegrias? Pacífico tu pecho y sosegado tranquilidad gustoso ha demostrado al paso que se aumenta tu hermosura. De tu llanto la pena y amargura ya no ofuscan las luces de tus ojos, que no vuelves tal vez, ni ahun con enojos, a aquel clima felíz, donde valiente nos habia de llevar dichosamente ese joven Francés. Ya no hablas nada de una tierra tan bella y cultivada, en donde las mujeres son servidas de un político pueblo y aplaudidas, recibiendo en amantes corazones a sus bellezas dignas atenciones: donde de sus Esposos compañeras reynan en todas partes placenteras: donde la libertad con el recato, el juicio sin violencia, y en su trato hallada la virtud sin los temores, quanto respiran, son honestas flores. Ya pues no suspirais por tan amada y dulce libertad antes deseada. ¿De un Sultan el serrallo violento su triste austeridad y el sentimiento, con que el nombre de esclava a el pecho asusta, no tiene nada odioso que os disgusta? ¿Acaso estimáis mas estas riberas que las del Sena siempre placenteras?

En la impresa en Barcelona es en estos terminos:

FATIMA.

Hermosa Zayda, extraño los afectos que de improviso esta mansion te inspira.

¿Qué destino felíz o qué esperanza ha cambiado los dias de horror llenos, en dias agradables y tranquilos?

Con tu belleza crece tu alegría, $\mathrm{y}$, las continuas lagrimas no turban la brillantez serena de tus ojos. Ya no los vuelves al dichoso clima, que aquel Francés gallardo nos pintaba, 


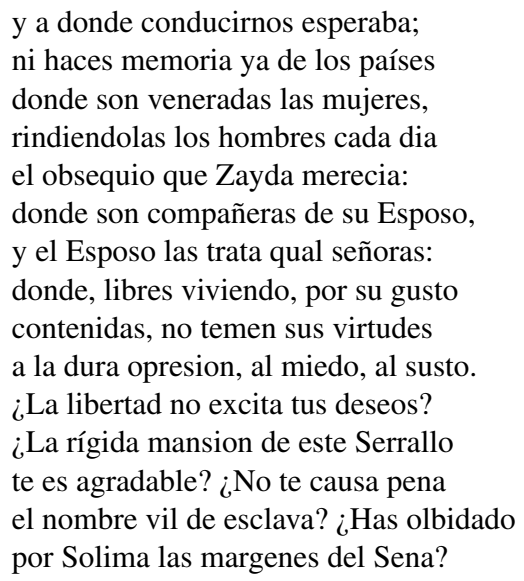

Me lisonjéo de la inclinacion, con que el público mira y recibe mis producciones, que en ésta disimulará las faltas, que no será extraño contenga, en consideracion a que no carece de dificultad este estudio, y a que yo no aspiro a otra satisfaccion en este trabajo, que a dar un nuevo testimonio del deseo que me aníma, de contribuir en quanto me es concedido, a la reforma del mal gusto, que ha reynado en esta parte entre nosotros hasta ahora.

\section{BiBLIOGRAFÍA CITADA}

\section{Textos}

García de la Huerta, Vicente (I784). «Advertencia del traductor», en La Fe triunfante del Amor y Cetro. Tragedia en que se ofrece a los aficionados la justa idea de una traducción poética. Por Vicente García de la Huerta. Madrid, Pantaleón Aznar, pp. [1]-[15].

- (I778). Endecasylabos, que recitó en la Real Academia de S. Fernando en la junta general que se celebró para la distribucion de premios el dia XXV de julio de MDCCLXXVIII D. Vicente Garcia de la Huerta [...]. S. 1., s. i., s. a.

- (I784). La Fe triunfante del Amor y Cetro. Tragedia en que se ofrece a los aficionados la justa idea de una traducción poética. Por Vicente García de la Huerta. Madrid, Pantaleón Aznar.

- (I778-I779). Obras poéticas. Madrid, Antonio de Sancha, 2 vols.

- (I786). Obras poeticas de D. Vicente Garcia de la Huerta. Segunda edicion. Tomo I. Tragedias. Suplemento al Theatro Hespañol. Con licencia, en Madrid, por Pantaleon Aznar, MDCCLXXXVI.

- Obras poeticas de D. Vicente Garcia de la Huerta. Segunda edicion. Tomo I. Tragedias. Suplemento al Theatro Hespañol. [Con una comedia inédita]. Edición de Jesús Cañas Murillo. En preparación.

- (1997). Poesías, edición, introducción y notas de Miguel Ángel Lama. Mérida, Editora Regional de Extremadura (Rescate, 14).

- (I785). Theatro Hespañol. Madrid, Imprenta Real, 15 vols.

- (2013). Theatro Hespañol. Prólogo del Colector. Edición, introducción y notas de Jesús Cañas Murillo. Málaga, Universidad de Málaga (Número monográfico. Anejos de Analecta Malacitana, 87. La escuela de los maridos. «Advertencia», en Obras de Don Nicolás y de Don Leandro Fernández de Moratín. Ed. Buenaventura Carlos Aribau. Madrid, Rivadeneyra (BAE, 2), 1846, pp. 442-443. 
[Fernández de Moratín, Leandro] (i798). Hamlet. Tragedia de Guillermo Shakespeare, traducida e ilustrada con la vida del autor y notas críticas por Inarco Celenio. Madrid, Villalpando.

[Fernández de Moratín, Leandro] (i 846). Hamlet, en Obras de Don Nicolás y de Don Leandro Fernández de Moratín. Ed. Buenaventura Carlos Aribau. Madrid, Rivadeneyra (BAE, 2), pp. 473-560. La «Advertencia», en pp. 473-475.

[Fernández de Moratín, LeAndro] (I8I2). La escuela de los maridos. Comedia escrita en francés por Juan Bautista Molière, y traducida a nuestra lengua por Inarco Celenio. Madrid, Villalpando.

[Fernández de Moratín, Leandro] (i8I4). El médico a palos. Comedia imitada por Inarco Celenio de la que escribió en francés J. B. Molière, con el título de El médico por fuerza. Madrid, I. Collado.

Jovellanos, GasPar Melchor De (I984). Obras completas. Tomo I. Obras literarias. Ed. José Miguel Caso González. Oviedo, Centro de Estudios del Siglo XVIII-Ilustre Ayuntamiento de Gijón (Colección de Autores Españoles del siglo XVIII, 22-1).

El médico a palos. «Advertencia», en Obras de Don Nicolás y de Don Leandro Fernández de Moratín. Ed. Buenaventura Carlos Aribau. Madrid, Rivadeneyra (BAE, 2), 1846, p. 460.

Obras de Don Nicolás y de Don Leandro Fernández de Moratín. Ed. Buenaventura Carlos Aribau. Madrid, Rivadeneyra (BAE, 2), 1846.

Voltaire (1838). Cándido o el optimismo. Traducido por Leandro Fernández de Moratín. Cádiz, Imp. de Santiponce.

\section{Estudios}

Állvarez Barrientos, Joaquín (2004). «Literatura y casticismo: Mor de Fuentes y su Ensayo de traducciones», en «Un hombre de bien». Saggi di lingue e letterature iberiche in onore di Rinaldo Froldi, I, a cura di Patrizia Garelli e Giovanni Marchetti. Bolonia, Edizioni dell»Orto, pp. 21-30.

Andioc, René y Mireille Coulon (2008). Cartelera teatral madrileña del siglo XVIII (17081808). Madrid, Fundación Universitaria Española, 2 vols., segunda edición corregida y aumentada.

Andioc, René (I993). «¿De estornudos, flatos, y otros modos de «dispersar». (Huerta y los fabulistas: un nuevo poema satírico)», Dieciocho, XVI, 1-2, pp. 25-48. Reimpreso en René Andioc, Del siglo XVIII al XIX. Estudios histórico-literarios, Zaragoza, Universidad de Zaragoza, 2005, pp. 347-373.

ANDIOC, ReNÉ (I996). «Más sobre traducciones castellanas de Molière en el siglo XVIII», en Teatro español del siglo XVIII. Ed. Josep Maria Sala Valldaura. Lérida, Universidad de Lérida, 2 vols., vol. I, pp. 45-63.

- (I979). «Moratín traducteur de Molière», en Hommage des Hispanistes Français a Nöel Salomon. Barcelona, Laia, pp. 49-72.

- (I982). «Sobre Goya y Moratín hijo», Hispanic Review, 50, 2 (spring 1982), pp. 119-132.

Cañas Murillo, Jesús (20I3). La disputa del Theatro Hespañol, de Vicente García de la Huerta: cronología de una controversia. Cáceres, Universidad de Extremadura (Trabajos del Departamento de Filología Hispánica, 28.

- (20I3). «Introducción» a Vicente García de La Huerta, Theatro Hespañol. Prólogo del Colector, edición, introducción y notas de Jesús Cañas Murillo. Málaga, Universidad de Málaga (Número monográfico. Anejos de Analecta Malacitana, 87), pp. 13-168.

- (I999). «Leandro Fernández de Moratín, traductor y adaptador dramático», Anuario de Estudios Filológicos, XXII, pp. 73-98. 
- (I999). «Leandro Fernández de Moratín, traductor dramático», en La traducción en España (1750-1830). Lengua, literatura, cultura. Ed. Francisco Lafarga. Lérida, Universidad de Lérida, pp. 463-475.

Cotarelo y Mori, Emilio (i897). Iriarte y su época. Madrid, Establecimiento Tipográfico «Sucesores de Rivadeneyra».

Deacon, Philip (I996). «La traducción de Hamlet de Leandro Fernández de Moratín», en Teatro clásico en traducción: texto, representación, recepción. Actas del Congreso Internacional. Murcia, 9-11 noviembre 1995. Edición de Ángel-Luis Pujante y Keith Gregor. Murcia, Universidad de Murcia, pp. 299-308.

LAFARGa, FrANCISCO (ED.) (1997). El teatro europeo en la España del siglo XVIII. Lérida, Universidad de Lérida.

- (I977). «Traducciones españolas de Zaire de Voltaire en el siglo XVIII», Revue de Littérature comparée, LI, pp. 343-355.

- (I982). Voltaire en España (1734-1835). Barcelona, Universidad de Barcelona (ver, especialmente, pp. 171-174).

Lama, Miguel Ángel (i990). «Vicente García de la Huerta desde la librería de Copín. Dos versiones inéditas de una sátira tremenda», Anuario de Estudios Filológicos, XIII, pp. 151-159.

Qualia, CH. B. (1939). «Voltaire»s Tragic Art in Spain in the XVIIIth. Century», Hispania, XXII, pp. 273-284.

Regalado Kerson, Pilar ( I989). «Leandro Fernández de Moratín: primer traductor de Shakespeare en castellano. Antecedentes y Preliminares a su versión de Hamlet», Dieciocho, 12, 1, pp. 45-65.

- (I989). «Moratín y Shakespeare: un ilustrado español ante el dramaturgo inglés», en Actas de IX Congreso de la Asociación Internacional de Hispanistas. Frankfurt am Main, Vervuert Verlag, 2 tomos; tomo II, pp. 75-83.

Ríos Carratalá, Juan Antonio (i988). «Introducción» a su edición de Raquel de Vicente García de la Huerta. Madrid, Cátedra (Letras Hispánicas, 5), pp. 9-62.

- (I987). Vicente García de la Huerta (1734-1787). Badajoz, Departamento de Publicaciones Diputación Provincial (Colección Rodríguez Moñino, 6). Segunda edición, 2009, en Biblioteca Virtual Miguel de Cervantes, http://bib.cervantesvirtual.com/FichaObra.html?Ref $=32316$.

Rossi, Giuseppe Carlo (1974). «Moratín traductor», en su libro Leandro Fernández de Moratín. Introducción a su vida y obra. Madrid, Cátedra, pp. 117-122.

Rodríguez, JuAn Carlos (I99i). Moratín o El arte nuevo de hacer teatro. Granada, Caja General de Ahorros.

Sabio Pinilla, José Antonio (ED.) (2009). La traducción en la época ilustrada (Panorámicas de la traducción en el Siglo XVIII). Granada, Editorial Comares (Interlingua).

Santos Zas, Margarita (I999). «De Zaïre de Voltaire a Xayra de García de la Huerta», en VV. AA., Homenaxe ó profesor Camilo Flores, tomo I. Santiago de Compostela, Universidad de Santiago de Compostela, pp. 457-479. 
